\title{
The Evaluation of Dynamic Airport Competitiveness Based on IDCQGA-BP Algorithm
}

\author{
Qiang Cui, ${ }^{1}$ Hai-bo Kuang, ${ }^{1}$ and ${\mathrm{Ye} \mathrm{Li}^{2}}^{2}$ \\ ${ }^{1}$ Transportation Management College, Dalian Maritime University, No. 1 Linghai Road, Dalian 116026, China \\ ${ }^{2}$ Faculty of Management and Economics, Dalian University of Technology, No. 2 Linggong Road, Dalian 116024, China \\ Correspondence should be addressed to Qiang Cui; cuiqiang1011@163.com
}

Received 25 August 2013; Accepted 30 November 2013

Academic Editor: Daoyi Dong

Copyright (c) 2013 Qiang Cui et al. This is an open access article distributed under the Creative Commons Attribution License, which permits unrestricted use, distribution, and reproduction in any medium, provided the original work is properly cited.

\begin{abstract}
Aimed at the multidimensional and complex characteristic of airport competitiveness, a new algorithm is proposed in which $\mathrm{BP}$ neural network is optimized by improved double chains quantum genetic algorithm (IDCQGA-BP). The new algorithm is better than existing algorithms in convergence and the diversity of quantum chromosomes. The empirical data of eight airports in Yangtze River Delta in 2011 and 2012 is applied to verify the feasibility of the new algorithm, and then the competitiveness of the eight airports from 2013 to 2015 is gotten through the algorithm. The results show the following. (1) The new algorithm is better than the existing optimization algorithms in the aspects of error accuracy and run time. (2) The gaps of the airports in Yangtze River Delta are narrowing; the competition and cooperation are getting stronger and stronger. (3) The main increase reason of airport competitiveness is the increase of own investment.
\end{abstract}

\section{Introduction}

In recent years, with the rapid development of China and the improvement of household consumption level, aviation demand has increased enormously in China. Many cities are planning to invest on new airports or on airport extension, which can offer convenience to people's travel and promote the development of Chinese economy. However, what about the competitiveness of Chinese airports over the years? It has become the center of public concern.

For the past few years, the evaluation of airport competitiveness has been a popular research topic. Lieshout and Matsumoto [1] use route choose model to analyze the probable reconstructs competitiveness of Tokyo Haneda Airport. The results show that Haneda Airport's market share in Japan and Asia-Pacific region will increase signally with the help of Japanese government. Park [2] uses fuzzy linguistic approach to evaluate eight main airports in East Asia from the aspects of geographical characteristics, access system, environmental effects, operational conditions of lines, regional development, availability of planning implementation, socioeconomic effects, and airport charges. Lee and Yang [3] analyze the strategy of Incheon Airport to be the logistic center of Northeast Asia; the results show that the key is whether Incheon Airport could attract sufficient global logistic service suppliers. Park [4] builds index system from the aspects of service, demand, management, facility and regional space, then evaluates the static competitiveness of the main airports in East Asia through multilayer decision model. Yeh et al. [5] build index system from the aspects of operational management, airport facility and consumer service quality, then analyze the static competitiveness of eleven Asia-Pacific airports through fuzzy multiple attribute evaluation method. Peng and Zhan [6] calculate the static airport competitiveness of Hangzhou airport and other AsiaPacific airports through AHP model. X. Y. Wu and K. Y. $\mathrm{Wu}$ [7] establishe AHP evaluation system and compare the advantages and disadvantages of five big airports in AsiaPacific Ocean and then give out some improvement measures for Pudong airport in Shanghai.

The disadvantages of existing research are as follows.

(1) The existing research mainly focuses on the evaluation of static airport competitiveness; the airport competitiveness under competition and cooperation has not been 
TABLE 1: The evaluation index system of dynamic airport competitiveness.

\begin{tabular}{|c|c|c|}
\hline Index classification & First-class indices & Second-class indices \\
\hline \multirow{8}{*}{$\begin{array}{l}\text { Index system of dynamic } \\
\text { airport competitiveness }\end{array}$} & \multirow[t]{3}{*}{ Regional influence } & $\begin{array}{l}\text { The proportion of business income divided by city third industry } \\
\text { output } V_{1} \\
\text { Paid tax } V_{2} \text { (hundred million yuans) }\end{array}$ \\
\hline & & Flight zone level $V_{3}^{1}$ \\
\hline & & The proportion of staff with college degree or above $V_{4}$ \\
\hline & \multirow[t]{2}{*}{ Own strength } & Total assets $V_{5}$ (hundred million yuans) \\
\hline & & $\begin{array}{l}\text { Investment amount } V_{6} \text { (hundred million yuans) } \\
\text { The number of nonexclusive service desks } V_{7}\end{array}$ \\
\hline & \multirow[t]{3}{*}{ Market condition } & $\begin{array}{l}\text { City resident transportation expense } V_{8} \\
\text { Average aircrafts movement in a day } V_{9} \text { (sorties/day) }\end{array}$ \\
\hline & & Service radius $V_{10}^{2}$ \\
\hline & & $\begin{array}{l}\text { Freight throughput } V_{11} \text { (ten thousand tons) } \\
\text { Passenger throughput } V_{12} \text { (ten thousand person-time) }\end{array}$ \\
\hline
\end{tabular}

evaluated, which leads to the difference between evaluated competitiveness and real competitiveness.

(2) Few pieces of literature have considered the error accuracy of evaluation method in the difference between evaluated competitiveness and real competitiveness. There are linear features and nonlinear features between airport competitiveness and its evaluation indices. However, few pieces of literature have considered nonlinear features, which may result in irrational results.

This paper is structured as follows: firstly, the evaluation index system of airport competitiveness is built; secondly, a new algorithm is proposed in which BP neural network is optimized by improved double chains quantum genetic algorithm (IDCQGA-BP); Thirdly, the real data of 8 Chinese airports in Yangtze River Delta region is applied to do the empirical study. Moreover, the advantages of the new algorithm over other evaluation methods are analyzed from the aspects of error precision and running time. Finally, the eight airports' dynamic competiveness from 2013 to 2015 is calculated through the new algorithm. The results show that the new algorithm has good applicability.

\section{Index System}

According to the existing literature $[8,9]$, the evaluation index system comes from three aspects: regional influence, own strength, and market condition. The index system is shown in Table 1.

Notes. (1) Flight zone level is defined as the biggest aircraft that the facilities of airport flight zone can support; it has two measurement indicators: the length of runway and the distance between the wingspan of the biggest supported airplane and the felly of main landing gear. In China, flight zone level is divided into several grades: $4 F, 4 E \cdot 60,4 E \cdot 45$, $4 D$, and $4 C$, and their measurable values are $5,4.5,4,3$, and 2 , respectively [9].

(2) Service radius is officially defined by Civil Aviation Administration of China as people amount within $100 \mathrm{~km}$ from airport or within 1.5 hours driving range. Service

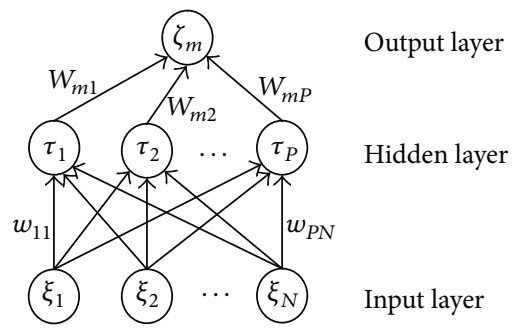

Figure 1: The structure of BP neural network.

radius is defined as people amount of the directly controlled municipalities and prefecture level cities in China [9].

According to the results of famous scholars and institutes $[10,11]$, the result-type measurement indices of competitiveness are market share and resource usage rate. So this paper defines main business income and return on asset as the ideal outputs.

\section{The Model}

3.1. BP Neural Network. The basic structure of BP neural network [12] is shown in Figure 1.

If the non-linear smooth activation function is defined as $g: R^{1} \rightarrow R^{1}$, the weight matrixes are defined as $W^{0}=$ $\left\{W_{m p}^{0}\right\}_{M \times P}$ and $\omega^{0}=\left\{\omega_{p n}^{0}\right\}_{1 \leq p \leq P, 1 \leq n \leq N}$; for any input $\xi=$ $\left(\xi_{1}, \ldots, \xi_{N}\right) \in R^{N}$, the real output is

$$
\varsigma_{m}^{0}=g\left(W_{m}^{0} \cdot \tau^{0}\right)=g\left(\sum_{p=1}^{P} W_{m p}^{0} \cdot \tau_{p}^{0}\right), \quad m=1,2, \ldots, M .
$$

The output of hidden layer is

$$
\tau_{P}^{0}=g\left(\omega_{p}^{0} \cdot \xi\right)=g\left(\sum_{n=1}^{N} \omega_{p n}^{0} \cdot \xi_{n}\right), \quad p=1,2, \ldots, P .
$$


If the input is $\left\{\xi_{j}\right\}_{j=1}^{J} \subset R^{N}$, its ideal output is $\left\{\mathrm{o}_{m}\right\}_{m=1}^{M} \subset$ $R^{M}$ and its real output of BP neural network is $\left\{\varsigma_{m}\right\}_{m=1}^{M} \subset R^{M}$; the error function can be defined as

$$
E(W, \omega)=\frac{1}{2} \sum_{m=1}^{M}\left\|\mathrm{o}_{m}-\varsigma_{m}\right\|^{2}
$$

\section{$\|\cdot\|$ is European Norm.}

Gradient descent algorithm (GDA) is the common method to train BP neural network. However, traditional gradient descent algorithm has some disadvantages in converging slowly and falling into the local minimum point easily [13]. Two methods are applied to improve GDA. (1) Gradient descent algorithm with momentums and adaptive variable rate: adaptive variable rate can accelerate the algorithm convergence, and momentums can reduce the shock and seek global optimum. (2) Some intelligent optimization algorithms can optimize the weights and threshold of BP neural network, which can accelerate the algorithm convergence and seek global optimum. The intelligent optimization algorithms contain genetic algorithm, particle swarm optimization, and so on.

3.2. The Evaluation Algorithm of Dynamic Airport Competitiveness Based on IDCQGA-BP. Quantum genetic algorithm (QGA) $[14,15]$ is a probability optimization algorithm based on the principle of quantum computing. It has been widely applied in combination optimization and function optimization. Double chains quantum genetic algorithm (DCQGA) is one kind of QGA and has been a popular research topic [16]. In DCQGA, the initial value of $\theta_{i j}$ of the quantum bit's probability amplitude $\left[\cos \theta_{i j}, \sin \theta_{i j}\right]^{T}$ is generated randomly in $(0,2 \pi), i=1,2, \ldots, n, j=1,2, \ldots, m . n$ stands for population size; $m$ stands for the number of quantum bits in each quantum chromosome. The phase is updated by quantum rotation gate and chromosomal mutation is realized by quantum nongate, which can enlarge the search space of quantum chromosome and accelerate the algorithm convergence.

According to literature [16-18], this paper proposes a new algorithm in which BP neural network is optimized by improved double chains quantum genetic algorithm (IDCQGA-BP). The new algorithm calculates the selective probability and the expectation reproduction rate of quantum chromosome through vector distance. The new algorithm can evaluate the dynamic airport competitiveness under competition and cooperation. Its principle is that IDCQGA$\mathrm{BP}$ algorithm calculates the existing airport competitiveness through existing data, and then the influence of existing competitiveness on the future competitiveness's evaluation indices is analyzed from the aspects of competition and cooperation. The future value of evaluation indices is gotten according to the influence, and then IDCQGA-BP is used to calculate the future airport competitiveness based on the future value of evaluation indices.

The steps of the algorithm are as follows.

(1) Initialize the quantum population. Choose $n$ quantum chromosomes with $m$ quantum bits in $(0, \pi / 2)$, which form the initial quantum population $X=\left\{x_{1}, x_{2}, \ldots, x_{n}\right\}$. The probability amplitude of each quantum bit is considered as two paratactic genes and each chromosome contains two paratactic gene chains; each gene chain stands for an optimal solution:

$$
x_{i}=\left|\begin{array}{c|c|c|c}
\cos \theta_{i 1} \\
\sin \theta_{i 1}
\end{array}\right| \begin{array}{c|c|c}
\cos \theta_{i 2} & \ldots & \cos \theta_{i m} \\
\sin \theta_{i 2} & \ldots & \sin \theta_{i m}
\end{array} \mid
$$

$\theta_{i j}=\pi / 2^{*}$ rand, where rand is the random number in $(0,1)$.

(2) Transform the solution space. In initial population, each quantum chromosome contains $2 m$ quantum bits probability amplitude. In this step, linear transformation is applied to map the $2 m$ quantum bits probability amplitude in $(0, \pi / 2)^{m}$ to the weight value space of BP neural network. According to literature [19], the initial value of the weights in BP neural network should be the random value in $[a, b]$. If the $j$ th quantum bit of quantum chromosome $x_{i}$ is $\left[\alpha_{j}^{i}, \beta_{j}^{i}\right]^{T}$, its corresponding value space vector is

$$
\begin{aligned}
& X_{j c}^{i}=a+(b-a) * \alpha_{j}^{i}, \\
& X_{j s}^{i}=a+(b-a) * \beta_{j}^{i},
\end{aligned}
$$

where $X_{j c}^{i}$ is the cosine solution of the $j$ th quantum bit of quantum chromosome $x_{i}, X_{j s}^{i}$ is the sine solution of the $j$ th quantum bit of quantum chromosome $x_{i}, \alpha_{j}^{i}$ is the probability amplitude of $X_{j c}^{i}$ corresponding to quantum state $|0\rangle$, and $\beta_{j}^{i}$ is the probability amplitude of $X_{j c}^{i}$ corresponding to quantum state $|1\rangle$.

(3) Calculate the vector distance and calculate the selective probability and the expectation reproduction rate of population $X$ based on vector distance concentration.

The vector distance of chromosome $x_{i}$ is

$$
\operatorname{dis}\left(x_{i}\right)=\sum_{k=1}^{n}\left|F\left(x_{i}\right)-F\left(x_{k}\right)\right| \text {. }
$$

The vector distance concentration is

$$
C\left(x_{i}\right)=\frac{1}{\operatorname{dis}\left(x_{i}\right)}=\frac{1}{\sum_{k=1}^{n}\left|F\left(x_{i}\right)-F\left(x_{k}\right)\right|} .
$$

The selective probability is

$P\left(x_{i}\right)=\frac{\operatorname{dis}\left(x_{i}\right)}{\sum_{i=1}^{n} \operatorname{dis}\left(x_{i}\right)}=\frac{\sum_{k=1}^{n}\left|F\left(x_{i}\right)-F\left(x_{k}\right)\right|}{\sum_{i=1}^{n} \sum_{k=1}^{n}\left|F\left(x_{i}\right)-F\left(x_{k}\right)\right|}$.

The expectation reproduction rate is

$$
e\left(x_{i}\right)=\frac{F\left(x_{i}\right)}{C\left(x_{i}\right)}=F\left(x_{i}\right) \sum_{k=1}^{n}\left|F\left(x_{i}\right)-F\left(x_{k}\right)\right| .
$$

(4) Sort the initial population $X$ according to the selective probability $P$ and the expectation reproduction rate $e$. The top ten quantum chromosomes that are high in expectation reproduction rate enter into new population $X_{\text {new }}$ and the $h$ quantum chromosomes whose selective probability is bigger 
than certain value $P_{r}\left(P_{r}=0.6 * \max (P)\right)$ enter into new population $X_{\text {new }}$. Then $n-10-h$ quantum chromosomes generated randomly in $(0, \pi / 2)$ enter into new population $X_{\text {new }}$.

(5) Update the quantum phase.

The formula is

$$
\left[\begin{array}{cc}
\cos (\Delta \theta) & -\sin (\Delta \theta) \\
\sin (\Delta \theta) & \cos (\Delta \theta)
\end{array}\right]\left[\begin{array}{c}
\cos (\theta) \\
\sin (\theta)
\end{array}\right]=\left[\begin{array}{c}
\cos (\theta+\Delta \theta) \\
\sin (\theta+\Delta \theta)
\end{array}\right],
$$

$\Delta \theta_{i}=-\operatorname{sgn}\left(\sin \left(\theta_{i}-\theta_{0}\right)\right) * \Delta \theta_{0} * \exp \left(-\left(\nabla F\left(x_{i}\right)-\right.\right.$ $\left.\left.\nabla F_{\text {min }}\right) /\left(\nabla F_{\max }-\nabla F_{\text {min }}\right)\right)$, where $\nabla$ is the gradient function; $\theta_{0}$ is the iterative initial value.

(6) Calculate the mutation. Quantum nongate is used to calculate the mutation. Choose a chromosome randomly from the population according to the mutation probability; then choose several quantum bits randomly in the selected chromosome and use quantum nongate to process selected quantum bits, which can exchange the two probability amplitudes of the quantum bit and calculate the two gene chains' mutation.

(7) Calculate the relevance degrees of the chromosomes. The relevance degree function is based on the error function of BP neural network. It is

$$
F\left(x_{i}\right)=\exp \left(-\frac{1}{2}\left\|\operatorname{tar}\left(x_{i}\right)-g\left(W * g\left(\omega * x_{i}\right)\right)\right\|^{2}\right),
$$

where tar is the ideal output of BP neural network, $W$ is the weight matrix between hidden layer and output layer, $\omega$ is the weight matrix between hidden layer and input layer, and $g$ is activation function.

(8) Revise the algorithm. Sort the quantum bit angel $\theta$ of all quantum chromosomes in $X_{\text {new }}$ and record the maximum $\theta_{\max }$ and minimum $\theta_{\min }$. If $\left|\theta_{\max }-\theta_{\min }\right|<\varepsilon$, then the value space should be reset as $(0, \pi / 2)$.

(9) Return to step (2) and repeat the rest steps until either the convergence condition or the maximum iteration step is satisfied.

(10) Use the trained BP neural network and the data at $t$ and $t-1$ to calculate the airport competitiveness $\operatorname{Com}(t)$ and $\operatorname{Com}(t-1)$.

(11) Normalize the main business income and return on assets at $t$ and $t-1$ and set their average value as the ideal output of BP neural network, which can be used to calculate the error accuracy of the algorithm.

(12) Analyze the influence of the airport competitiveness at $t$ on the evaluation indices at $t+1$ and estimate the value of the indices at $t+1$. There are two aspects. (1) Competition. The key point is to analyze the influence of existing competitiveness on the future market shares of this airport and other airports. (2) Cooperation. The key point is to analyze the influence of the cooperation on international lines on the future market shares of this airport and other airports.

(1) Competition. According to literature [9], if airport $A$ and airport $B$ have direct competition (the service radiuses of the two airports have overlap), then the competitiveness of airport $A$ will influence the future market conditions of airport $A$ and airport $B$. In the same way, the competitiveness of airport $B$ will influence the future market conditions of airport $A$ and airport $B$.

If there are $N$ airports in a region whose service radiuses have overlap and the competitiveness of the $N$ airports at $t$ is $\left(\mathrm{Com}_{1}(t), \mathrm{Com}_{2}(t), \ldots, \mathrm{Com}_{N}(t)\right)$ and the competitiveness

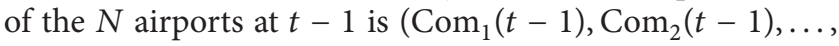
$\left.\operatorname{Com}_{N}(t-1)\right)$, the competitiveness change of airport $i$ from $t-1$ to $t$ will influence the market share of airport $i$ at $t+1$. The change value 1 of passenger throughput $V_{12}$ at $t+1$ is

$$
\left(\frac{\operatorname{Com}_{i}(t)}{\sum_{i=1}^{N} \operatorname{Com}_{i}(t)}-\frac{\operatorname{Com}_{i}(t-1)}{\sum_{i=1}^{N} \operatorname{Com}_{i}(t-1)}\right) * V_{12}(i t) .
$$

Similarly, the change value 1 of freight throughput $V_{11}$, the change value 1 of average aircrafts movement in a day $V_{9}$, the change value 1 of business income $V_{01}$, the change value 1 of paid tax $V_{2}$, and the change value 1 of total assets $V_{5}$ are

$$
\begin{aligned}
& \left(\frac{\operatorname{Com}_{i}(t)}{\sum_{i=1}^{N} \operatorname{Com}_{i}(t)}-\frac{\operatorname{Com}_{i}(t-1)}{\sum_{i=1}^{N} \operatorname{Com}_{i}(t-1)}\right) * V_{11}(i t), \\
& \left(\frac{\operatorname{Com}_{i}(t)}{\sum_{i=1}^{N} \operatorname{Com}_{i}(t)}-\frac{\operatorname{Com}_{i}(t-1)}{\sum_{i=1}^{N} \operatorname{Com}_{i}(t-1)}\right) * V_{9}(i t), \\
& \left(\frac{\operatorname{Com}_{i}(t)}{\sum_{i=1}^{N} \operatorname{Com}_{i}(t)}-\frac{\operatorname{Com}_{i}(t-1)}{\sum_{i=1}^{N} \operatorname{Com}_{i}(t-1)}\right) * V_{01}(i t), \\
& \left(\frac{\operatorname{Com}_{i}(t)}{\sum_{i=1}^{N} \operatorname{Com}_{i}(t)}-\frac{\operatorname{Com}_{i}(t-1)}{\sum_{i=1}^{N} \operatorname{Com}_{i}(t-1)}\right) * V_{2}(i t), \\
& \left(\frac{\operatorname{Com}_{i}(t)}{\sum_{i=1}^{N} \operatorname{Com}_{i}(t)}-\frac{\operatorname{Com}_{i}(t-1)}{\sum_{i=1}^{N} \operatorname{Com}_{i}(t-1)}\right) * V_{5}(i t) .
\end{aligned}
$$

(2) Cooperation. In a region, some airports are international hub airports, and some are regional airports. The cooperation among the airports is embodied in the cooperation on international lines between international hub airports and regional airport. The international lines of the $N$ airports at $t$ are $\operatorname{In}_{1}(t)$, In $t_{2}(t), \ldots, \operatorname{In}_{N}(t)$; the bigger the proportion of airport $i$ 's international lines is, the more cooperation benefits airport $i$ can get. So the change value 2 of passenger throughput $V_{12}$ at $t+1$ is

$$
\frac{\text { In }_{i}}{\sum_{i=1}^{N} \text { In }_{i}} * \sum_{i=1}^{N} V_{12}(i t) * p_{t} * \theta_{t}
$$

where $p_{t}$ is the proportion of the passenger throughput of international lines divided by the total passenger throughput and $\theta_{t}$ is the natural population growth rate of the region.

Similarly, the change value 2 of freight throughput $V_{11}$, the change value 2 of average aircrafts movement in a day $V_{9}$, 
the change value 2 of business income $V_{01}$, the change value 2 of paid $\operatorname{tax} V_{2}$, and the change value 2 of total assets $V_{5}$ are

$$
\begin{aligned}
& \frac{\mathrm{In}_{i}}{\sum_{i=1}^{N} \mathrm{In} \mathrm{t}_{i}} * \sum_{i=1}^{N} V_{11}(i t) * p_{t} * \theta_{t} \text {, } \\
& \frac{\text { In }_{i}}{\sum_{i=1}^{N} \text { In }_{i}} * \sum_{i=1}^{N} V_{9}(i t) * p_{t} * \theta_{t} \\
& \frac{\text { In }_{i}}{\sum_{i=1}^{N} \text { In t }_{i}} * \sum_{i=1}^{N} V_{01}(i t) * p_{t} * \theta_{t} \text {, } \\
& \frac{\text { In }_{i}}{\sum_{i=1}^{N}{\text { In } t_{i}}_{i=1}^{N}} \sum_{i=1}^{N}(i t) * p_{t} * \theta_{t} \\
& \frac{\mathrm{In}_{i}}{\sum_{i=1}^{N} \mathrm{Int}_{i}} * \sum_{i=1}^{N} V_{5}(i t) * p_{t} * \theta_{t} .
\end{aligned}
$$

According to the results of competition and cooperation, the passenger throughput of airport $i$ at $t+1$ is

$$
\begin{aligned}
& V_{12}(i(t+1)) \\
& =V_{12}(i t)+\left(\frac{\operatorname{Com}_{i}(t)}{\sum_{i=1}^{N} \operatorname{Com}_{i}(t)}-\frac{\operatorname{Com}_{i}(t-1)}{\sum_{i=1}^{N} \operatorname{Com}_{i}(t-1)}\right) * V_{12}(i t) \\
& \quad+\frac{\mathrm{Int}_{i}}{\sum_{i=1}^{N} \operatorname{Int}_{i}} * \sum_{i=1}^{N} V_{12}(i t) * p_{t} * \theta_{t} .
\end{aligned}
$$

The freight throughput $V_{11}$, the average aircrafts movement in a day $V_{9}$, the business income $V_{01}$, the paid $\operatorname{tax} V_{2}$, and the total assets $V_{5}$ at $t+1$ are

$$
\begin{aligned}
& V_{11}(i(t+1)) \\
& =V_{11}(i t)+\left(\frac{\operatorname{Com}_{i}(t)}{\sum_{i=1}^{N} \operatorname{Com}_{i}(t)}-\frac{\operatorname{Com}_{i}(t-1)}{\sum_{i=1}^{N} \operatorname{Com}_{i}(t-1)}\right) \\
& \quad * V_{11}(i t)+\frac{\operatorname{Int}_{i}}{\sum_{i=1}^{N} \operatorname{Int}_{i}} * \sum_{i=1}^{N} V_{11}(i t) * p_{t} * \theta_{t}, \\
& V_{9}(i(t+1)) \\
& =V_{9}(i t)+\left(\frac{\operatorname{Com}_{i}(t)}{\sum_{i=1}^{N} \operatorname{Com}_{i}(t)}-\frac{\operatorname{Com}_{i}(t-1)}{\sum_{i=1}^{N} \operatorname{Com}_{i}(t-1)}\right) \\
& * V_{9}(i t)+\frac{\operatorname{In~t}_{i}}{\sum_{i=1}^{N} \operatorname{Int}_{i}} * \sum_{i=1}^{N} V_{9}(i t) * p_{t},
\end{aligned}
$$

TABLE 2: The parameters of IDCQGA-BP.

\begin{tabular}{lc}
\hline Input neurons & 12 \\
Hidden neurons & 20 \\
Output neurons & 1 \\
Weights & 260 \\
Population size & 1000 \\
Mutation rate & 0.1 \\
Initial phase & $0.01 \pi$ \\
Target error & 0.01 \\
Max iterations & 5000 \\
{$[a, b]$} & {$[0,0.38]$} \\
$\varepsilon$ & 0.0001 \\
\hline
\end{tabular}

$$
\begin{aligned}
& V_{01}(i(t+1)) \\
& =V_{01}(i t)+\left(\frac{\operatorname{Com}_{i}(t)}{\sum_{i=1}^{N} \operatorname{Com}_{i}(t)}-\frac{\operatorname{Com}_{i}(t-1)}{\sum_{i=1}^{N} \operatorname{Com}_{i}(t-1)}\right) \\
& \quad * V_{01}(i t)+\frac{\mathrm{Int}_{i}}{\sum_{i=1}^{N} \operatorname{Int}_{i}} * \sum_{i=1}^{N} V_{01}(i t) * p_{t} * \theta_{t}, \\
& V_{2}(i(t+1)) \\
& =V_{2}(i t)+\left(\frac{\operatorname{Com}_{i}(t)}{\sum_{i=1}^{N} \operatorname{Com}_{i}(t)}-\frac{\operatorname{Com}_{i}(t-1)}{\sum_{i=1}^{N} \operatorname{Com}_{i}(t-1)}\right) \\
& \quad * V_{2}(i t)+\frac{\operatorname{Int}_{i}}{\sum_{i=1}^{N} \operatorname{Int}_{i}} * \sum_{i=1}^{N} V_{2}(i t) * p_{t} * \theta_{t}, \\
& V_{5}(i(t+1)) \\
& =V_{5}(i t)+\left(\frac{\operatorname{Com}_{i}(t)}{\sum_{i=1}^{N} \operatorname{Com}_{i}(t)}-\frac{\operatorname{Com}_{i}(t-1)}{\sum_{i=1}^{N} \operatorname{Com}_{i}(t-1)}\right) \\
& * V_{5}(i t)+\frac{\operatorname{Int}_{i}}{\sum_{i=1}^{N} \operatorname{Int}_{i}} * \sum_{i=1}^{N} V_{5}(i t) * p_{t} * \theta_{t} .
\end{aligned}
$$

Then, according to their historical growth rates, this paper predicts the future value of flight zone level, the proportion of staff with college degree or above, investment amount, the number of nonexclusive service desks, city resident transportation expense, service radius, and city third industry output.

(13) Set the indices calculated in step (12) as the network inputs, and then use the BP neural network trained in step (10) to calculate the dynamic airport competitiveness under competition and cooperation at $t+1$.

The main improvements are embodied in the following. (1) The initial value of phase is randomly selected in $(0, \pi / 2)$ instead of $(0,2 \pi)$ and the value space of $\theta$ is revised at step (8). It can reduce the search space of the algorithm signally and assure the algorithm's faster convergence. (2) The selective probability and expectation reproduction rate calculated by vector distance can increase the diversity of 
TABLE 3: The results in 2011.

\begin{tabular}{lcccccccc}
\hline Airports & Shanghai Pudong & Shanghai Hongqiao & Ningbo & Hefei & Hangzhou & Nanjing & Wenzhou & Wuxi \\
\hline Target value & 0.5513 & 0.3404 & 0.0667 & 0.0585 & 0.2329 & 0.1739 & 0.0745 & 0.0391 \\
BP & 0.6207 & 0.4898 & 0.1237 & 0.0954 & 0.3615 & 0.2044 & 0.1011 & 0.0594 \\
QGA-BP & 0.5090 & 0.4310 & 0.0882 & 0.0472 & 0.2448 & 0.1855 & 0.0909 & 0.0532 \\
DCQGA-BP & 0.5409 & 0.3930 & 0.0678 & 0.0496 & 0.2945 & 0.1818 & 0.0891 & 0.0498 \\
IDCQGA-BP & 0.5622 & 0.3641 & 0.0732 & 0.0597 & 0.2116 & 0.1691 & 0.0727 & 0.0367 \\
\hline
\end{tabular}

TABLE 4: The results in 2012.

\begin{tabular}{lcccccccc}
\hline Airports & Shanghai Pudong & Shanghai Hongqiao & Ningbo & Hefei & Hangzhou & Nanjing & Wenzhou & Wuxi \\
\hline Target value & 0.5745 & 0.3631 & 0.1183 & 0.0735 & 0.2625 & 0.1847 & 0.0858 & 0.0395 \\
BP & 0.6386 & 0.4098 & 0.1398 & 0.0996 & 0.3115 & 0.2052 & 0.1062 & 0.0602 \\
QGA-BP & 0.5370 & 0.3910 & 0.1088 & 0.0868 & 0.3048 & 0.1955 & 0.1003 & 0.0578 \\
DCQGA-BP & 0.6109 & 0.3830 & 0.1278 & 0.0696 & 0.2813 & 0.1618 & 0.0991 & 0.0502 \\
IDCQGA-BP & 0.5922 & 0.3741 & 0.1032 & 0.0697 & 0.2416 & 0.1791 & 0.0827 & 0.0387 \\
\hline
\end{tabular}

quantum chromosomes and can reduce the search space of $\theta$. Then, according to literature [19], this paper sets the initial weight's value range of BP neural network as $[a, b]$ (in the numerical computation, it is $[0,0.38])$, which can accelerate the convergence.

\section{The Case}

4.1. The Data. The basic data in this paper comes from eight airports in Yangtze River Delta in 2011 and 2012. The eight airports are Shanghai Pudong airport, Shanghai Hongqiao airport, Ningbo Lishe airport, Hefei Luogang airport, Hangzhou Xiaoshan airport, Nanjing Lukou airport, Wenzhou Yongqiang airport, and Wuxi Shuofang airport. The data of service radius comes from the definition. Because Shanghai Pudong airport is listed airport, its "proportion of staff with college degree or above," "total assets," "investment amount," "return on asset," "freight throughput," "passenger throughput," "aircraft movements," and "main business income" come from annual report. The data of other airports comes from research report and network data. Other data comes from the statistical yearbook of the city.

4.2. The Advantages and Disadvantages of the Algorithms. The activation function is $1 /(1+\exp (-2 x))$; other parameters of IDCQGA-BP are shown in Table 2.

In order to analyze the advantages and disadvantages of IDCQGA-BP, this paper uses BP neural network [12], BP neural network optimized by quantum genetic algorithm (QGA-BP) [20-22], BP neural network optimized by double chains quantum genetic algorithm (DCQGA-BP) [16] and BP neural network optimized by improved double chains quantum genetic algorithm (IDCQGA-BP) to evaluate the airport competitiveness. The ideal output is defined as the average value of normalized main business income and normalized return on asset. This paper runs the four algorithms ten times based on the real data in 2011 and 2012. The results are the average value of the ten results, as shown in Tables 3 and 4 .
From Tables 3 and 4, we can get the following conclusions. (1) In Yangtze River Delta, Shanghai Pudong airport is an international hub airport, Shanghai Hongqiao airport, Hangzhou Xiaoshan airport, and Nanjing Lukou airport are regional hub airports, and Ningbo Lishe airport, Hefei Luogang airport, Wenzhou Yongqiang airport, and Wuxi Shuofang airport are feeder airports. These conclusions are the same as those in literature [23]. (2) All the eight airports' competitiveness has increased from 2011 to 2012, but the increase rates are different. Ningbo Lishe airport's increase rate is the biggest (41\%); the main increase reason is the increase of market condition. Then the medial ones are those of Hefei Luogang airport (16.75\%), Hangzhou Xiaoshan airport (14.18\%), and Wenzhou Yongqiang airport (13.76\%). Their main increase reason is the improvement of regional influence. The smaller ones are those of Shanghai Pudong airport (5.34\%), Shanghai Hongqiao airport (2.75\%), and Wuxi Shuofang airport (5.45\%). Their main increase reason is the improvement of own strength, especially the increase of own investment.

The errors and running times are shown in Table 5.

From Table 5, it can be concluded that IDCQGA-BP is better than the existing optimization algorithms in the aspects of error accuracy and run time.

4.3. Dynamic Airport Competitiveness. In this paper, the airport competitiveness in 2011 and 2012 is the initial value to analyze the dynamic airport competitiveness of the eight airports in Yangtze River Delta from 2013 to 2015. This paper supposes that the flight zone levels of the eight airports from 2013 to 2015 are the same as those in 2012. The average increase rate of "the proportion of staff with college degree or above" is $15.2 \%$ based on the historical data from 2008 to 2012. The average increase rate of "investment amount" is $13.2 \%$; the number of nonexclusive service desks remains unchanged. The average increase rate of "city resident transportation expense" is $11.08 \%$ based on the city statistical yearbook. The average increase rate of "service radius" is $2.8 \%$ and the average increase rate of "third industry output" is $17.7 \%$. 
TABLE 5: The errors and running times of the four algorithms.

\begin{tabular}{lcccc}
\hline Algorithms & Maximum error & Minimum error & Average error & Average running time (s) \\
\hline BP & 1.156 & 0.560 & 0.714 & 11.539 \\
QGA-BP & 0.784 & 0.425 & 0.592 & 7.891 \\
DCQGA-BP & 0.629 & 0.162 & 0.301 & 6.560 \\
IDCQGA-BP & 0.627 & 0.146 & 0.287 & 6.195 \\
\hline
\end{tabular}

TABLE 6: The overlap conditions of the eight airports' service radius.

\begin{tabular}{|c|c|c|c|c|c|c|c|c|}
\hline Overlap or not & Pudong & Hongqiao & Ningbo & Hefei & Hangzhou & Nanjing & Wenzhou & Wuxi \\
\hline Pudong & - & 1 & 1 & 0 & 1 & 0 & 0 & 1 \\
\hline Hongqiao & 1 & - & 1 & 0 & 1 & 0 & 0 & 1 \\
\hline Ningbo & 1 & 1 & - & 0 & 1 & 0 & 0 & 0 \\
\hline Hefei & 0 & 0 & 0 & - & 0 & 1 & 0 & 0 \\
\hline Hangzhou & 1 & 1 & 1 & 0 & - & 0 & 0 & 1 \\
\hline Nanjing & 0 & 0 & 0 & 1 & 0 & - & 0 & 1 \\
\hline Wenzhou & 0 & 0 & 0 & 0 & 0 & 0 & - & 0 \\
\hline Wuxi & 1 & 1 & 0 & 0 & 1 & 1 & 0 & - \\
\hline
\end{tabular}

Note. 1 stands for overlap, 0 stands for no overlap.

The overlap conditions of the eight airports' service radius are shown in Table 6.

The international lines of the eight airports in 2012 are shown in Table 7.

The proportion of the passenger throughput in international lines divided by the total passenger throughput is $p_{t}=20.2 \%$. Based on the increase rate analysis, this paper uses IDCQGA-BP algorithm to calculate the airport competitiveness of the eight airports in Yangtze River Delta from 2013 to 2015, as shown in Table 8.

As shown in Table 8, the eight airports' competitiveness has increased from 2013 to 2015, but the increase rates are different. The average increase rate of Wuxi Shuofang airport is the biggest; then the medial ones are those of Hefei Luogang airport and Ningbo Lishe airport. The smaller ones are those of Hangzhou Xiaoshan airport, Nanjing Lukou airport, and Wenzhou Yongqiang airport. The smallest ones are those of Shanghai Pudong airport and Shanghai Hongqiao airport. The competitiveness of feeder airports increases signally, whose average increase rate $(17.44 \%)$ is bigger than international hub airport (3.32\%) and regional hub airports $(6.94 \%)$. The average increase rate of regional hub airports is bigger than international hub airport. The gaps of the airports in Yangtze River Delta are narrowing; the competition and cooperation are getting stronger and stronger. The main increase reason of Wuxi airport is the increase of own investment. More investment could lead to software and hardware conditions upgrade and help attract more airlines, especially international flights. More investment could assure more open aero policies. However, blind extension should be avoided and more measures should be taken from the aspects of improving resource usage efficiency such as the efficiency of capital, flights, and human resources.

\section{Conclusion}

In this paper, the airport competitiveness when airports are facing competition and cooperation is studied. The empirical study is based on the data of eight airports in Yangtze River Delta in 2011 and 2012, and the eight airports' dynamic competitiveness under competition and cooperation from 2013 to 2015 is calculated. The average increase rate of feeder airports is bigger than international hub airport and regional hub airports. The average increase rate of regional hub airports is bigger than international hub airport. The gaps of the airports in Yangtze River Delta are narrowing; the competition and cooperation are getting stronger and stronger.

On the whole, the contribution of this paper to the literature is embodied in two aspects. Firstly, a new algorithmIDCQGA-BP algorithm-is proposed. From the results, it can be concluded that IDCQGA-BP is better than the existing optimization algorithms in the aspects of error accuracy and run time. IDCQGA-BP has satisfactory imitative effect and high accuracy; its applicability has been verified. Secondly, The paper simulates the influence of competition and cooperation on airports' market share and calculates the dynamic airport competitiveness when airports are facing competition and cooperation. It fills the gap of the existing literature in which only static airport competitiveness has been evaluated and lays good foundation for evaluating dynamic airport competitiveness reasonably.

However, it should be noted that the parameter selection process has certain randomness. This paper runs the algorithm ten times to minimize the effect caused by this randomness, but this will increase the workload. Future research could focus on avoiding the randomness to reduce the workload. 
TABLE 7: The international lines of the eight airports in 2012.

\begin{tabular}{lcccccccc}
\hline Airports & Shanghai Pudong & Shanghai Hongqiao & Ningbo & Hefei & Hangzhou & Nanjing & Wenzhou & Wuxi \\
\hline Number & 93 & 10 & 13 & 8 & 27 & 18 & 7 & 7 \\
\hline
\end{tabular}

TABLE 8: The dynamic airport competitiveness of the eight airports from 2013 to 2015.

\begin{tabular}{lcccccccc}
\hline Airports & Shanghai Pudong & Shanghai Hongqiao & Ningbo & Hefei & Hangzhou & Nanjing & Wenzhou & Wuxi \\
\hline 2013 & 0.6254 & 0.3905 & 0.1204 & 0.0965 & 0.2535 & 0.1847 & 0.0993 & 0.0547 \\
2014 & 0.6544 & 0.4197 & 0.1449 & 0.1172 & 0.2703 & 0.1951 & 0.1025 & 0.0666 \\
2015 & 0.6675 & 0.4252 & 0.1637 & 0.1362 & 0.2913 & 0.2201 & 0.1138 & 0.0883 \\
Average increase rate (\%) & 3.3194 & 4.3940 & 16.6617 & 18.8312 & 7.1982 & 9.2223 & 7.1235 & 27.1688 \\
\hline
\end{tabular}

\section{Acknowledgments}

This research is funded by National Nature Science Foundation of China (nos. 71073016, 71273037, and 71320107006) and the Fundamental Research Funds for the Central Universities (no. 3132013336) and supported by Program for Liaoning Innovative Research Team in University.

\section{References}

[1] R. Lieshout and H. Matsumoto, "New international services and the competitiveness of Tokyo International Airport," Journal of Transport Geography, vol. 22, pp. 53-64, 2012.

[2] Y. Park, "An analysis for the competitive strength of Asian major airports," Journal of Air Transport Management, vol. 9, no. 6, pp. 353-360, 2003.

[3] H. Lee and H. M. Yang, "Strategies for a global logistics and economic hub: Incheon International Airport," Journal of Air Transport Management, vol. 9, no. 2, pp. 113-121, 2003.

[4] Y. Park, "Application of a fuzzy linguistic approach to analyse Asian airports' competitiveness," Transportation Planning and Technology, vol. 20, no. 4, pp. 291-309, 1997.

[5] C.-H. Yeh, Y.-L. Kuo, and Y.-H. Chang, "Fuzzy multiattribute evaluation of airport performance," in Proceedings of the IEEE International Conference on Fuzzy Systems (FUZZ '11), pp. 26302637, June 2011.

[6] J. L. Peng and C. X. Zhan, "A case study on evaluation of airport logistics competitiveness based on AHP," Advanced Materials Research, vol. 159, pp. 307-312, 2011.

[7] X. Y. Wu and K. Y. Wu, "Study on the competency of Shanghai Pudong Airport in Asia-Pacific Ocean with AHP," Logistics Technology, vol. 9, pp. 203-206, 2005.

[8] C. Cheng, K. S. Li, and R. Liu, "Research on the elements and enhancement measures of airport competitiveness: the case of Guangzhou Baiyun International Airport," Industrial \& Science Tribune, vol. 11, no. 2, pp. 24-25, 2012.

[9] Q. Cui, H. B. Kuang, C. Y. Wu, and Y. Li, "Dynamic formation mechanism of airport competitiveness: the case of China," Transportation Research A, vol. 47, no. 1, pp. 10-18, 2013.

[10] S. Garelli, Top Class Competitors, Orient Press, Beijing, China, 2008.

[11] P. F. Ni, Chinese City Competitiveness Blue Book 2010: China City Competitiveness Report, Social Sciences Documentation Publishing House, Beijing, China, 2010.

[12] W. Wu, Neural Network Computation, Higher Education Press, Beijing, China, 2007.
[13] FECIT Technological Product Research Center, Neural Network Theory and MATLAB 7 Application, Publishing House of Electronics Industry, Beijing, China, 2005.

[14] R. P. Feynman, "Simulating physics with computers," International Journal of Theoretical Physics, vol. 21, no. 6-7, pp. 467-488, 1982.

[15] K.-H. Han and J.-H. Kim, "Quantum-inspired evolutionary algorithm for a class of combinatorial optimization," IEEE Transactions on Evolutionary Computation, vol. 6, no. 6, pp. 580-593, 2002.

[16] S. Y. Li and P. C. Li, Quantum Computation and Quantum Optimization Algorithms, Harbin Institute of Technology Press, Harbin, China, 2009.

[17] M. X. Sun and X. P. Chen, "A immune algorithm based on the vector distance applied to function optimization," Journal of Suzhou University Engineering Science Edition, vol. 30, no. 3, pp. 56-57, 2010.

[18] B. Wang, Z. Zhang, F. Li, Y. Sun, and H. Ding, "Comprehensive evaluation of regulated deficit irrigation using projection pursuit model based on improved double chains quantum genetic algorithm," Transactions of the Chinese Society of Agricultural Engineering, vol. 28, no. 2, pp. 84-89, 2012.

[19] S. Qiao and Z. H. Dong, "A method of choosing BP network's initial weights," Journal of Northeast Normal University, vol. 36, no. 3, pp. 25-30, 2004.

[20] Q. Zuo, S. S. Ye, R. C. Guo, and H. Shi, "Using quantum genetic algorithm to improve BP learning algorithm," Computer System \& Applications, vol. 2009, no. 5, pp. 53-55, 2009.

[21] Y. G. Cai, M. J. Zhang, H. Cai, and Y. Zhang, "Hybrid chaotic quantum evolutionary algorithm," Systems EngineeringTheory \& Practice, vol. 32, no. 10, pp. 2207-2214, 2012.

[22] Y.-H. Li and Y.-P. Wang, "An effective hybrid quantum genetic algorithm," Systems Engineering-Theory \& Practice, vol. 26, no. 11, pp. 116-124, 2006.

[23] Y. B. Yang and S. Zhong, "A classification of Chinese civil airports," Airport, vol. 11, pp. 39-42, 2004. 


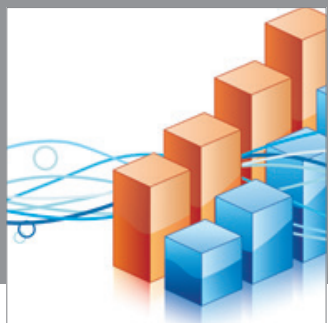

Advances in

Operations Research

mansans

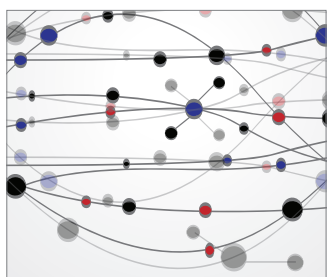

The Scientific World Journal
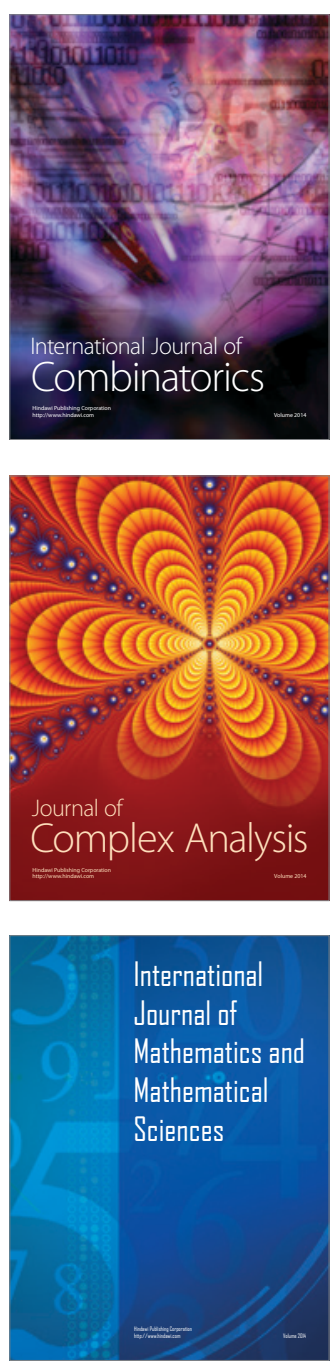
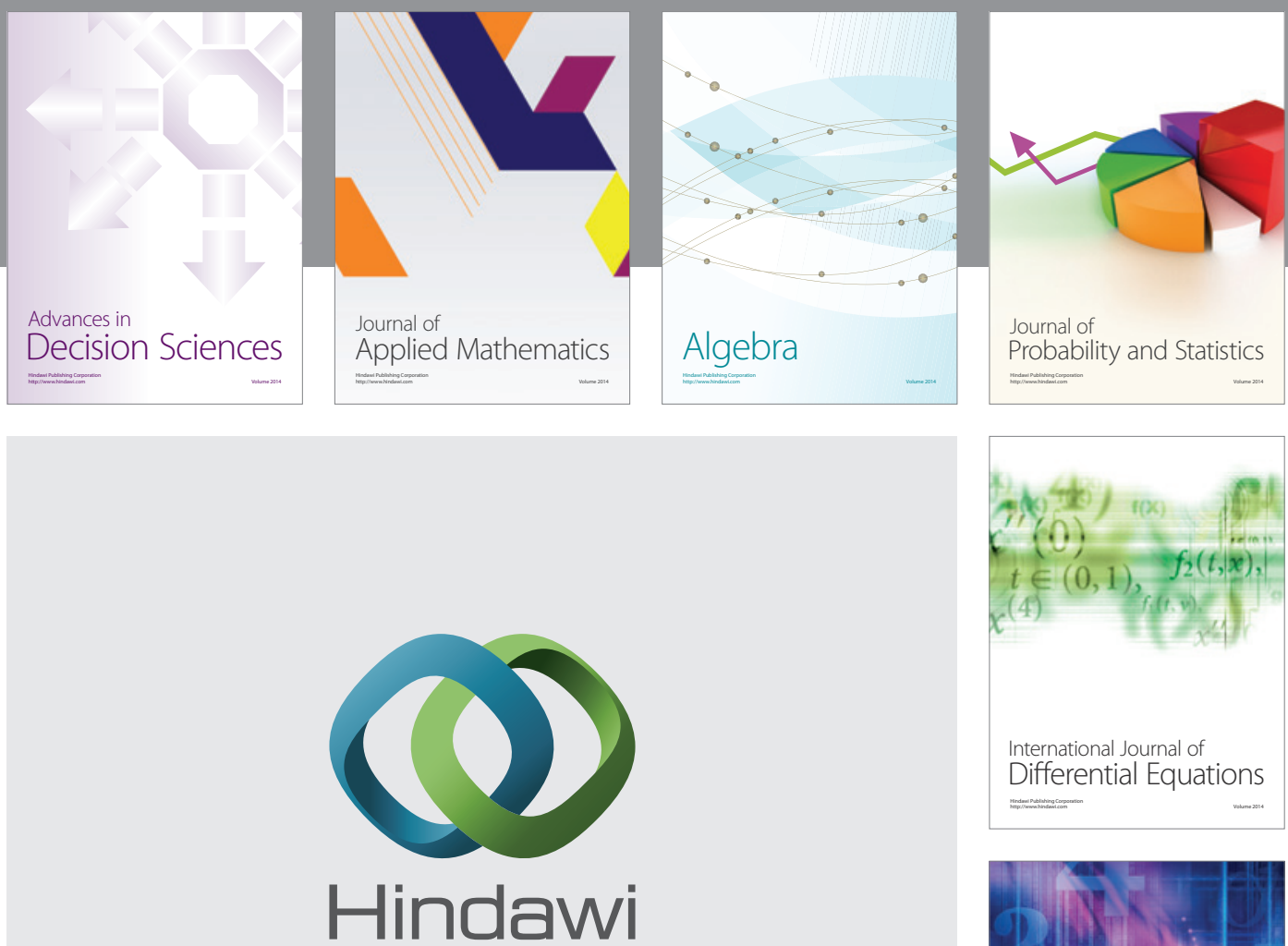

Submit your manuscripts at http://www.hindawi.com
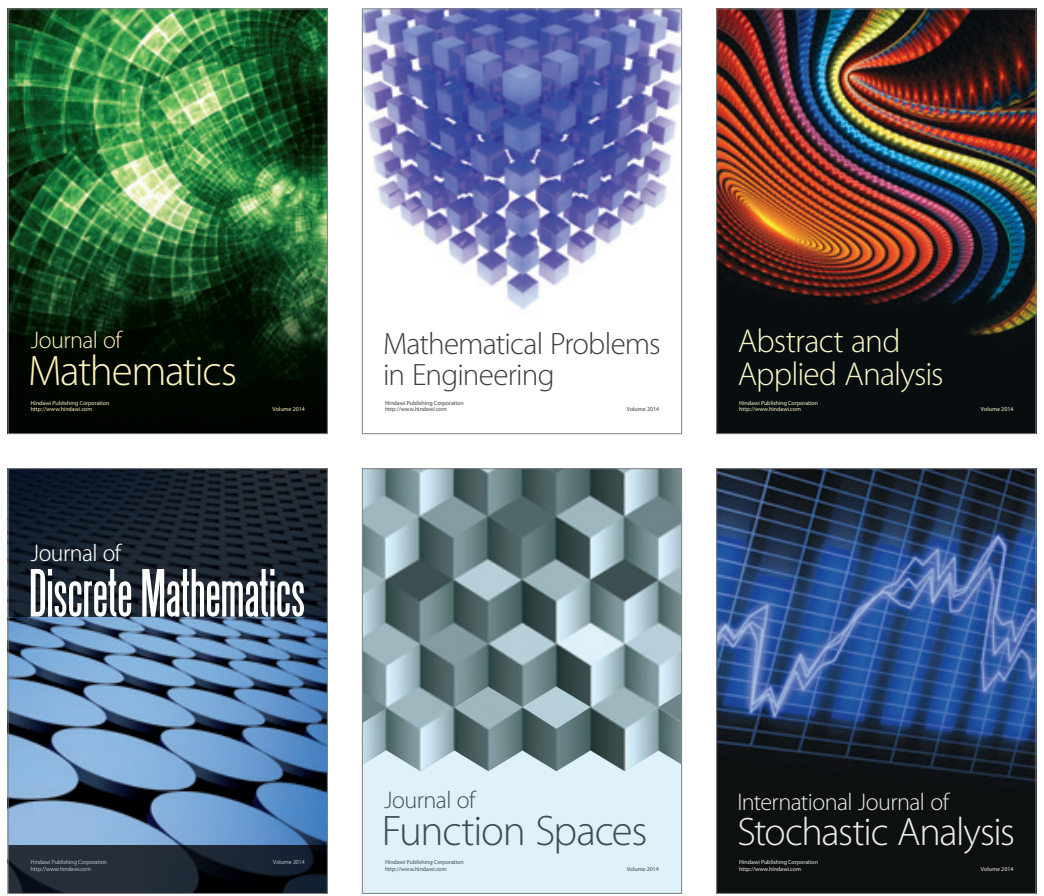

Journal of

Function Spaces

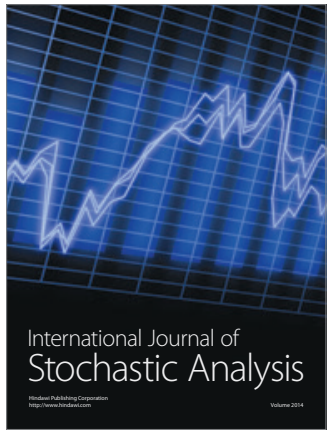

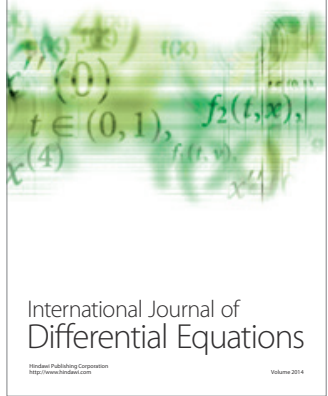
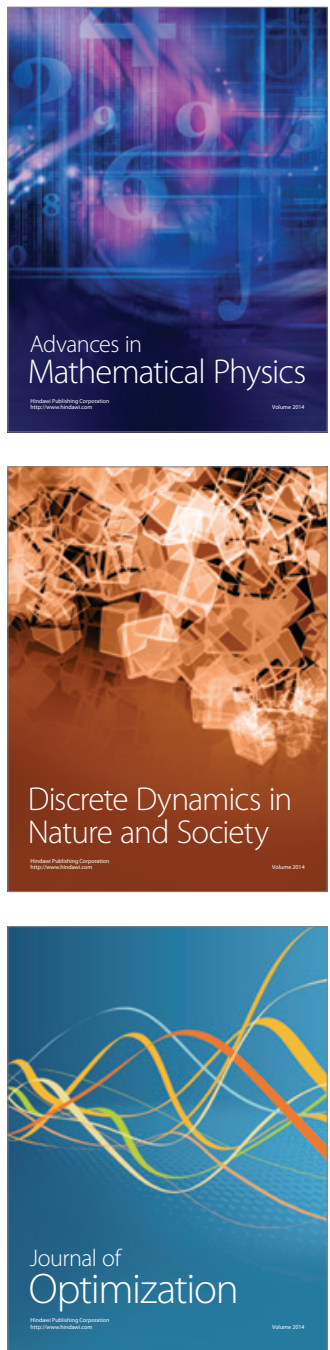